\title{
Inhibitory effect of ursolic acid and oleanolic acid from Eriobotrya fragrans on A549 cell viability in vivo
}

\author{
Y.S. Gao ${ }^{1,2 *}$, Y. Yuan ${ }^{1,2 *}$, G. Song ${ }^{3}$ and S.Q. Lin $^{1,2}$ \\ ${ }^{1}$ State Key Laboratory for Conservation and Utilization of Subtropical \\ Agro-Bioresources, South China Agricultural University, Guangzhou, \\ Guangdong, China \\ ${ }^{2}$ College of Horticulture, South China Agricultural University, \\ Guangzhou, Guangdong, China \\ ${ }^{3}$ Cancer Research Center, Xiamen University Medical College, \\ Xiamen, Fujian, China \\ *These authors contributed equally to this study. \\ Corresponding author: S.Q. Lin \\ E-mail: loquat@scau.edu.cn
}

Genet. Mol. Res. 15 (2): gmr. 15028642

Received March 23, 2016

Accepted April 11, 2016

Published May 13, 2016

DOI http://dx.doi.org/10.4238/gmr.15028642

\begin{abstract}
Loquat [Eriobotrya japonica (Lindl.)] is a traditional Chinese medicine, which has been used as an anti-inflammatory and for curing chronic bronchitis among other potential applications. Extracted ursolic acid (UA) and oleanolic acid (OA) from wild loquat were previously found capable of suppressing the proliferation of A549 cells in vitro. In the current study, nude mice were used to determine the inhibitory effect of UA and OA on tumor formation in vivo. The results demonstrate that $\mathrm{UA}$ and $\mathrm{OA}$ reduced the proliferation of A549 cells in nude mice, and increased the expression of Bid while decreasing the protein levels of MMP-2, Ki-67, and CD34. In this study, we identified potential antitumor activity in a wild loquat extract containing UA and $\mathrm{OA}$, which demonstrates that
\end{abstract}


traditional Chinese medicine may have a role in treating certain types of cancer.

Key words: Wild loquat; Ursolic acid; Oleanolic acid; Nude mice; A549 cell; Lung cancer

\section{INTRODUCTION}

Accompanied by the global environmental deterioration, especially in the developing countries, lung cancer is a fatal malignancy worldwide. Discovery of potential natural antineoplastic drugs that have minimal side effects is the goal of many ongoing cancer research studies. Ursolic acid (UA) is a natural pentacyclic triterpenoid carboxylic acid, oleanolic acid (OA) has a similar structure as UA, OA has methyl group on C20, and UA has a methyl group on C19 (Figure 1) (Es-Saady et al., 1994). UA and OA have been isolated from and identified in Eriobotrya japonica, and also in plants including Rosmarinus officinalis and Glechoma hederaceae (Liu, 1995). The pharmacological properties of OA and UA include anti-oxidative effects (Liobikas et al., 2011; Checker et al., 2012), anti-allergic effects (Kim et al., 2009), hepatic and neural protection (Li et al., 2013), anti-inflammatory effects (Sultana and Saify, 2012), and anti-tumor activity (Wang et al., 2011).

A
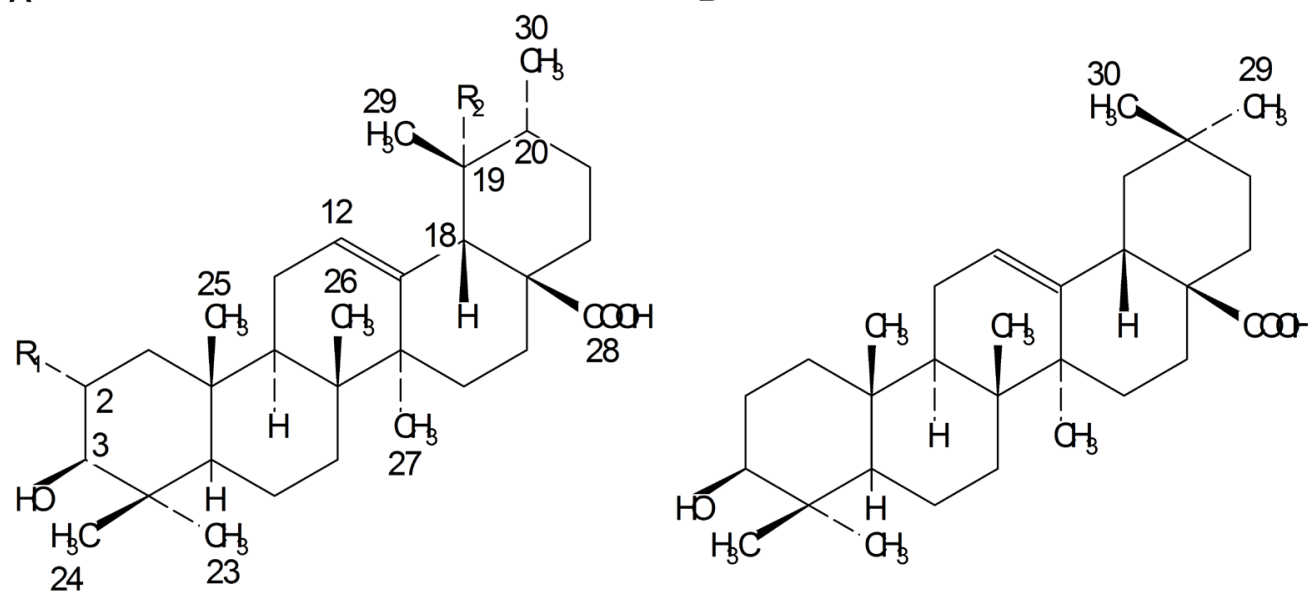

Figure 1. Chemical structures of the isomeric triterpenoids. A. Ursolic acid (R1, R2 = H) and B. oleanolic acid.

Pentacyclic triterpenoids are present at high concentration in loquat leaves. Loquat [Eriobotrya japonica (Lindl.)] originated in China, where it is considered as an important economic fruit. Loquat leaves are an effective natural medicine that has traditionally been utilized to treat diseases, including asthma and chronic bronchitis (Ito et al., 2000). Our study has shown that the concentration of UA and OA in the leaves of some wild loquat species is much higher than that found in other common loquat species, for example, in Eriobotrya fragrans Champ. (Hong and Lin, 2007). 
To date, there is minimal information available on the effect of authentic UA and OA extracted from wild loquat on lung cancer cells. We previously reported that UA and OA isolated from the leaves of wild loquat E. fragrans were able to inhibit A549 cell survival and induce apoptosis (Yuan et al., 2015). This study evaluated the effects of UA and OA isolated from E. fragrans Champ. in a nude mice xenograft model. Moreover, this study was specifically designed to further verify the inhibitory effect of UA and OA on A549 cells in vivo.

\section{MATERIAL AND METHODS}

\section{Reagents}

UA and OA were extracted from the leaves of wild loquat E. fragrans Champ. (Hong et al., 2008). UA and OA were dissolved in ethanol to prepare separate $0.01 \mathrm{M}$ stock solutions, followed by storage of the stock solutions at $-20^{\circ} \mathrm{C}$. Each stock solution was diluted in phosphate buffer saline (PBS) before using.

\section{Cell culture}

Cell culture of the A549 cells was prepared as previously described (Yuan et al., 2015).

\section{Human lung carcinoma xenograft in nude mice}

The in vivo experiments with 30 female Balb/c nude mice $(20 \pm 2 \mathrm{~g})$ were carried out in the Cancer Research Center, Medical College of Xiamen University, the mice used in this experiment were originated from Xiamen University. All procedures involving the mice were conducted in strict compliance with relevant laws, the Animal Welfare Act, Public Health Services Policy, and guidelines established by the Institutional Animal Care and Use Committee of the university. The xenograft model was established by injecting cultured A549 cells. Five nude mice were used in each treatment arm. A549 cells ( $2 \times 10^{6} /$ mouse) were implanted via subcutaneous injection into the right foreleg. After 7 days, the mice were injected subcutaneously with test article every other day for 2 weeks.

\section{Animal study treatment phase}

Normal saline was used as the negative control, and CY $(50 \mathrm{mg} / \mathrm{kg})$ was selected as positive control. The active study arms were low-dose UA and OA $(50 \mathrm{mg} / \mathrm{kg})$ and high-dose UA and OA $(100 \mathrm{mg} / \mathrm{kg})$. At the end of the $23 \mathrm{rd}$ day of the experimental period, the mice were sacrificed by cervical dislocation. The tumors were removed and weighed, and the tumor volume was recorded. The tumor tissues were then fixed and stored.

\section{Measurement of tumor size}

The diameters of developing tumors were measured in situ by vernier calipers once every two days. The tumor volume was calculated using the formula: $\mathrm{V}=0.5 \mathrm{ab}^{2}$, where ' $\mathrm{a}$ ' and ' $b$ ' are the major and minor diameter, respectively. 


\section{Immunohistochemical staining}

Following removal of the subcutaneous neoplasm and metastases, the tissues were fixed in $10 \%$ formaldehyde, and then embedded in paraffin. The sections were cut, and immunohistochemical staining was performed as previously described (Song et al., 2005). PBS was used as the negative control, instead of primary antibodies.

\section{Statistical analysis}

Calculations were carried out using the Microsoft Excel software. The statistical significance was evaluated by GraphPad Prism with $\mathrm{P}<0.05$ considered significant.

\section{RESULTS}

\section{Proliferation of A549 cells is inhibited by UA/OA in nude mice}

Upon completion of the 16-day treatment in 6 separate groups of animals, the volume and weight of transplanted tumors were measured. As shown in Figure 2A, UA and OA suppressed the proliferation of A549 cells in nude mice. There were no significant effects across the groups with respect to body weight (data not shown). Compared to the negative control, both UA and OA (at both the low and high concentrations) inhibited the growth of tumors to a similar degree as the positive control, CY. The arm with the smallest tumor volume was the high-dose UA group (Figure 2B). Furthermore, tumor weight of the high-dose UA group was generally similar to the tumor weight of the positive control group, CY (Figure 2C). Finally, it is important to note that the tumor weights for all the active treatment groups were markedly lower than that of the control group and reached statistical significance $[\mathrm{P}<$ 0.05 ) in the $\mathrm{CY}$ and UA high dose groups (Figure 2C)]. However, the effect of high-dose UA and $\mathrm{OA}$ on the reduction of spontaneous lung cancer metastasis in liver samples could not be accurately quantified ( $\underline{\text { S1 Figure }})$.

\section{Immunohistochemical staining}

To further understand the mechanism through which UA and OA influence tumor formation, the tumor tissues in the high dose groups were examined by hematoxylin staining to evaluate Bid, MMP-2, Ki-67, and CD34 expression. The results showed that UA and OA decreased the expression of MMP-2, Ki-67, and CD34 and increased Bid expression. Additionally, it appears that based on immunohistochemical staining examination, the magnitude of response was greater following UA (high dose) treatment than that following OA (high dose) treatment (Figure 3).

\section{DISCUSSION}

Loquat is an important fruit crop in China and Japan and is cultivated in the whole Mediterranean basin (southern Europe, Middle East, and northern Africa). It has traditionally been used in natural medicine as an anti-inflammatory agent and for the treatment of asthma 
A
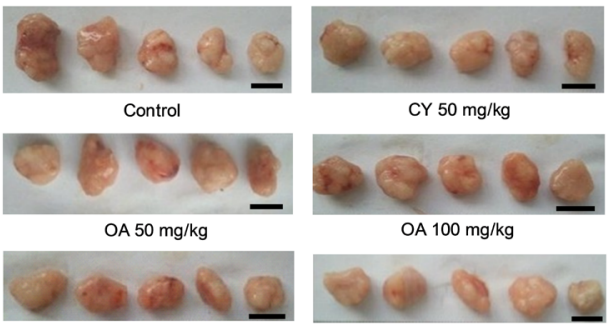

$\mathrm{OA} 100 \mathrm{mg} / \mathrm{kg}$

UA $50 \mathrm{mg} / \mathrm{kg}$
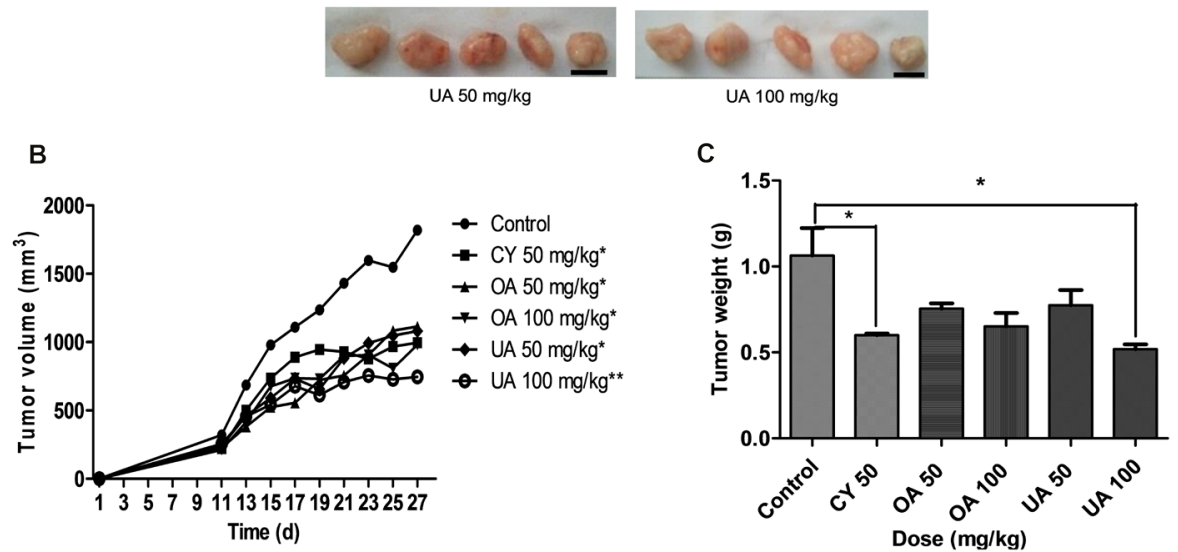

Figure 2. Observation and measurement of the tumors from mice fed different substances. A. Photographs of tumor samples treated with different doses of the substances. Control group received normal saline alone, CY was selected as the positive control, the black bar in each photo stands for $1 \mathrm{~cm}$. B. Volume of tumor samples. C. Weight of tumor samples. Data are reported as means \pm S.D. $\mathrm{N}=$ five treated mice. $* \mathrm{P}<0.05$.

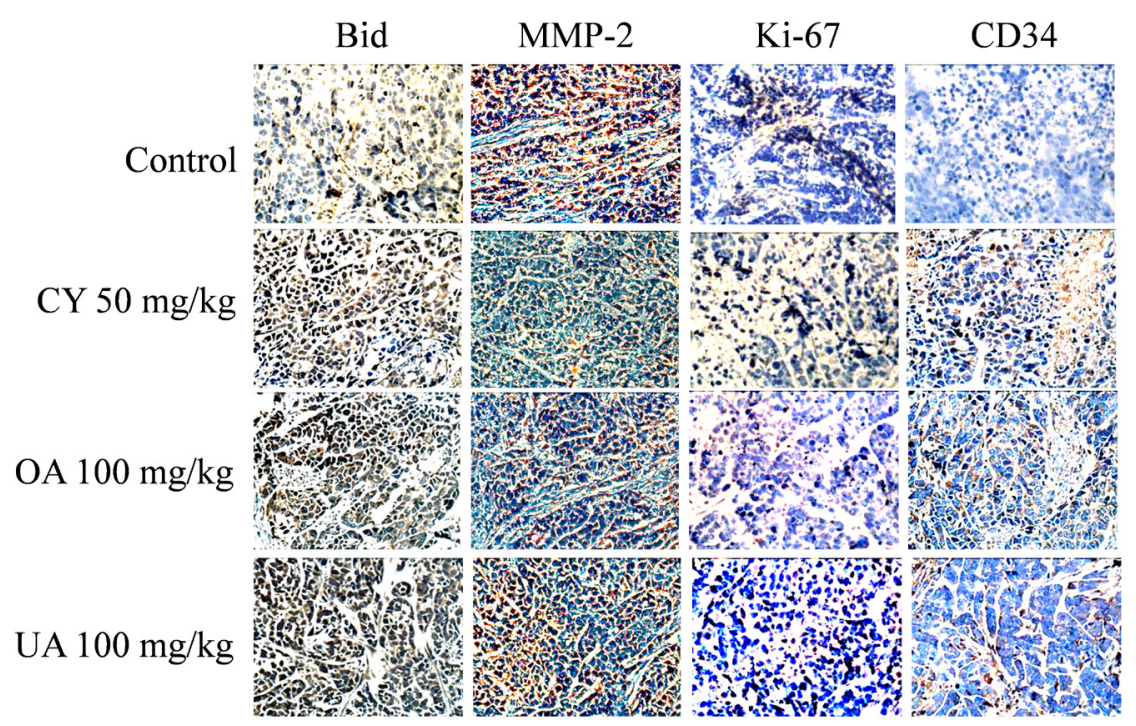

Figure 3. Proliferation of A549 cells was inhibited by UA and OA in nude mice. Tumor samples of control, CY and UA $100 \mathrm{mg} / \mathrm{kg}$ and OA $100 \mathrm{mg} / \mathrm{kg}$ were immunohistochemically stained with anti-Bid, anti-MMP-2, anti-Ki-67, anti-CD34, and analyzed by hematoxylin and eosin staining (40X). 
and chronic bronchitis. UA and OA are the major components in the extracts of loquat leaves and possess antibacterial, anti-inflammatory, and antifungal properties (Shyu et al., 2010). The Loquat Germplasm Resources Nursery of South China Agricultural University has collected about 30 varieties of wild loquats worldwide. Our previous studies showed that the UA and OA content in some varieties of wild loquat leaves are higher than their contents in most common loquat leaves (Hong and Lin, 2007). Therefore, leaves from wild loquat trees could be viewed as a more efficient resource to obtain active material, including UA and OA, for potential natural medicinal applications.

This study demonstrated the effects of UA and OA, extracted from E. fragrans Champ. on the reduction of in vivo growth of an A549 xenograft in nude mice. Antigen Ki67 is a nuclear protein associated with ribosomal RNA transcription and is necessary for cell proliferation. Antigen Ki-67 is commonly used to determine the growth fraction in a cell population and is often correlated with the clinical course for a number of cancers (Schonk et al., 1989; Rahmanzadeh et al., 2007). CD34 is a heavily glycosylated, transmembrane glycoprotein, that serves as a cell-cell adhesion factor and is expressed on hematopoietic and vascular-associated tissues (Nielsen and McNagny, 2008). Both UA and OA at high doses decreased the number of MMP-2-, Ki-67-, and CD34-postive cells, while increasing the number of Bid-positive cells. The above cellular mechanism may explain the efficacy of UA and OA in reducing the A549 cancer cell's viability, proliferation, invasion, and migration. However, it appears as though neither UA nor OA at high doses could prevent cancer metastasis in the liver (S1 Figure). As previously reported (Yuan et al., 2015), the immunohistochemical staining results showed that UA and OA could inhibit the cancer cell proliferation to the same extent as the positive control CY. This result further supports the notion that UA and OA are potential natural medicine candidates for inhibiting tumor growth. Based on these results, UA was more effective than OA in inhibiting cancer cell proliferation. The underlying mechanistic explanation of why UA is more effective than OA is unknown. Potential reasons for different efficacy findings for UA and OA could include intracellular binding affinity to various intracellular components involved in the cell cycle process or differences in pharmacokinetic properties including absorption and tissue distribution. Future studies are needed to better understand these hypotheses. However, to further complicate interpretation of the study results, the nude mice used in this study had detectable populations of functional T cells and NK cells. Based on these study results, we cannot discount the possibility that UA and OA exhibited their effects via stimulation of the intrinsic immune system, thereby inhibiting tumor growth. Future work requires assessment of the effects of UA and OA on tumor growth in other immuno-compromised mice models for example the Rag2-/-gc-/- model that lack all the components of the T/B/NK innate immune system.

The extracted UA and OA were capable of inducing cell apoptosis. This suggests that wild loquat is a potentially effective therapeutic herb, both in traditional Chinese and western medicine. Using wild loquat to replace cultivated varieties can result in a deficiency of wild loquat leaves while also causing a decline in cultivated loquat fruit production resulting in a loss of farmers' earning.

\section{Conflicts of interest}

The authors declare no conflicts of interest. 


\section{ACKNOWLEDGMENTS}

Research supported by the State Key Laboratory for Conservation and Utilization of Subtropical Agro-bioresources (\#201504010028, from Guangzhou municipal government) and the Innovation and Utilization for Germplasm Resources of Guangdong (\#2014A030304057, \#2015A030303015).

\section{REFERENCES}

Checker R, Sandur SK, Sharma D, Patwardhan RS, et al. (2012). Potent anti-inflammatory activity of ursolic acid, a triterpenoid antioxidant, is mediated through suppression of NF- $\mathrm{B}, \mathrm{AP}-1$ and NF-AT. PLoS One 7: e31318. http:// dx.doi.org/10.1371/journal.pone.0031318

Es-Saady D, Najid A, Simon A, Denizot Y, et al. (1994). Effects of ursolic acid and its analogues on soybean 15-lipoxygenase activity and the proliferation rate of a human gastric tumour cell line. Mediators Inflamm. 3: 181-184. http://dx.doi. org/10.1155/S0962935194000244

Hong YP and Lin SQ (2007). Determination of ursolic acid in Eriobotrya leaves and terpenoid. Acta Hortic. 750: $225-232$. http://dx.doi.org/10.17660/ActaHortic.2007.750.35

Hong YP, Qiao YC, Lin SQ, Jiang YM, et al. (2008). Characterization of antioxidant compounds in Eriobotrya fragrans Champ leaf. Sci. Hortic. (Amsterdam) 118: 288-292. http://dx.doi.org/10.1016/j.scienta.2008.06.018

Ito Y, Pandey P, Place A, Sporn MB, et al. (2000). The novel triterpenoid 2-cyano-3,12-dioxoolean-1,9-dien-28-oic acid induces apoptosis of human myeloid leukemia cells by a caspase-8-dependent mechanism. Cell Growth Differ. 11: 261-267.

Kim SH, Kwon YE, Park WH, Jeon H, et al. (2009). Effect of leaves of Eriobotrya japonica on anaphylactic allergic reaction and production of tumor necrosis factor-alpha. Immunopharmacol. Immunotoxicol. 31: 314-319. http:// dx.doi.org/10.1080/08923970802714775

Li L, Zhang X, Cui L, Wang L, et al. (2013). Ursolic acid promotes the neuroprotection by activating Nrf2 pathway after cerebral ischemia in mice. Brain Res. 1497: 32-39. http://dx.doi.org/10.1016/j.brainres.2012.12.032

Liobikas J, Majiene D, Trumbeckaite S, Kursvietiene L, et al. (2011). Uncoupling and antioxidant effects of ursolic acid in isolated rat heart mitochondria. J. Nat. Prod. 74: 1640-1644. http://dx.doi.org/10.1021/np200060p

Liu J (1995). Pharmacology of oleanolic acid and ursolic acid. J. Ethnopharmacol. 49: 57-68. http://dx.doi. org/10.1016/0378-8741(95)90032-2

Nielsen JS and McNagny KM (2008). Novel functions of the CD34 family. J. Cell Sci. 121: 3683-3692. http://dx.doi. org/10.1242/jcs.037507

Rahmanzadeh R, Hüttmann G, Gerdes J and Scholzen T (2007). Chromophore-assisted light inactivation of pKi-67 leads to inhibition of ribosomal RNA synthesis. Cell Prolif. 40: 422-430. http://dx.doi.org/10.1111/j.1365-2184.2007.00433.x

Schonk DM, Kuijpers HJ, van Drunen E, van Dalen CH, et al. (1989). Assignment of the gene(s) involved in the expression of the proliferation-related Ki-67 antigen to human chromosome 10. Hum. Genet. 83: 297-299. http:// dx.doi.org/10.1007/BF00285178

Shyu MH, Kao TC and Yen GC (2010). Oleanolic acid and ursolic acid induce apoptosis in HuH7 human hepatocellular carcinoma cells through a mitochondrial-dependent pathway and downregulation of XIAP. J. Agric. Food Chem. 58: 6110-6118. http://dx.doi.org/10.1021/jf100574j

Song G, Mao YB, Cai QF, Yao LM, et al. (2005). Curcumin induces human HT-29 colon adenocarcinoma cell apoptosis by activating p53 and regulating apoptosis-related protein expression. Braz. J. Med. Biol. Res. 38: 1791-1798. http:// dx.doi.org/10.1590/S0100-879X2005001200007

Sultana Nand SaifyZS(2012). Naturally occurring and syntheticagents as potential anti-inflammatory and immunomodulants. Antiinflamm. Antiallergy Agents Med. Chem. 11: 3-19. http://dx.doi.org/10.2174/187152312803476264

Wang X, Zhang F, Yang L, Mei Y, et al. (2011). Ursolic acid inhibits proliferation and induces apoptosis of cancer cells in vitro and in vivo. J. Biomed. Biotechnol. 2011: 419343. http://dx.doi.org/10.1155/2011/419343

Yuan Y, Gao Y, Song G and Lin S (2015). Ursolic acid and oleanolic acid from Eriobotrya fragrans inhibited the viability of A549 cells. Nat. Prod. Commun. 10: 239-242. 


\section{Supplementary material}

S1 Figure. The formation of micrometastasis. The livers of untreated and treated $(\mathrm{OA}, \mathrm{UA}, 100 \mathrm{mg} / \mathrm{kg}) \mathrm{mice}$. The formations were shown as arrows. 